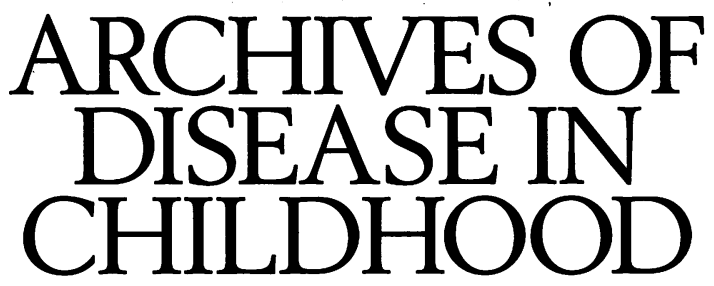

The fournal of the British Paediatric Association

\title{
Annotations
}

\section{Pollution: does it cause asthma?}

The epidemiology of asthma has some puzzling features that could shed light on the causation of the disease. ${ }^{1}$ Hospital admission rates have risen steeply during recent years in many countries, particularly among children, and the rise does not seem to be explained by any tendency to admit milder cases. Where surveys of asthma have been repeated after an interval of 10 or more years in the same area, using the same methodology as before, a rise in prevalence has been found; it is particularly striking that these increases have been observed in all parts of the world. Comparative studies conducted in different areas have shown geographical differences in asthma prevalence. We do not know why these increases and differences occur; presumably some environmental factors are responsible, and it seems reasonable to suspect variations in air quality as a possible cause.

\section{Specific pollutants}

Polluted air contains a mixture of various substances, the most important in this context being as follows:

(1) Oxides of nitrogen - principally nitric oxide and nitrogen dioxide - are emitted in motor vehicle exhaust fumes and hence occur in congested streets. They are also produced by power stations and other industrial sources, cigarette smoking, and gas cookers, which can produce high concentrations indoors.

(2) Ozone is produced by the action of sunlight on nitrogen dioxide in the presence of hydrocarbons, which (like nitrogen dioxide) are in car exhaust fumes. Paradoxically, ozone concentrations may be higher in rural areas than in city centres, partly because excess nitric oxide in the city reacts with ozone to produce nitrogen dioxide and oxygen, and partly because nitrogen dioxide laden air is blown into the countryside where it is more freely exposed to sunlight.

(3) Sulphur dioxide is emitted from power stations and other industrial sources burning coal and oil. When oxidised in the atmosphere (for example, by the action of ozone) it forms sulphuric acid, a major ingredient of acid aerosols.

(4) Particulates are produced by the combustion of coal and oil and are found in diesel emissions. The larger particulates are the most obvious (for example, in black smoke), but it is the smaller ones (less than $10 \mu \mathrm{m}$ diameter or $\mathrm{PM}_{10}$ ) that reach the lungs and are the greatest threat to health.

\section{Epidemiological evidence}

It is not in doubt that acute episodes of severe atmospheric pollution cause respiratory symptoms, especially in patients who suffer from asthma. It is also accepted that chronic exposure to air pollution can have long term adverse effects in patients with chronic obstructive airways disease. What is uncertain is whether pollution causes asthma, as distinct from exacerbating the disease in people who are already asthmatic.

It might be expected that epidemiological evidence would show clearly whether or not air pollution was associated with the prevalence of asthma. Pollutants can be measured fairly accurately and show wide geographical differences. Asthma prevalence can be estimated by means of questionnaires and various provocation tests. Numerous studies have compared the prevalence of asthma in different areas with varying levels of air pollution. The results seem to be strangely conflicting.

Several studies have reported a higher prevalence of asthma or wheeze in urban and industrialised areas than in less polluted areas. ${ }^{2-5}$ Hay fever also seems - surprisingly to be more common in urban than in rural areas, ${ }^{46}$ suggesting that air pollution could potentiate allergy. A higher prevalence of asthma and poorer lung function values were found in children living in an area of Austria with high ozone concentrations in comparison with another area. ${ }^{7}$ The prevalence of cedar pollinosis in different areas of Japan is related both to the volume of local traffic and to the proximity of cedar trees. ${ }^{8} \mathrm{~A}$ study of preschool children in Birmingham showed an association between hospital admission for asthma and residence in an area with high traffic flow; there was also a significant linear trend in the relationship between asthma admissions and traffic volume for children living within $500 \mathrm{~m}$ of a main road. ${ }^{9}$ A German survey of 2050 schoolchildren found that both wheezing and allergic rhinitis were associated with traffic density, even when the data were controlled for potential confounders such as active and passive smoking. ${ }^{10}$ Norwegian children exposed to industrial sulphur dioxide had a higher prevalence of atopy and bronchial hyperreactivity than children living in an unpolluted but otherwise similar area. ${ }^{11}$

Indoor sources may also be relevant: one study reported that children in houses with gas cookers were more likely to have physician diagnosed asthma (but not wheeze without 
a diagnosis of asthma) than other children, ${ }^{12}$ while in another study children with newly diagnosed asthma were exposed to more indoor nitrogen dioxide (as shown by monitoring badges) than controls. ${ }^{13}$ In both these studies the asthmatic children were also exposed to more environmental tobacco smoke.

On the other hand, a number of surveys have reported that polluted areas do not have a higher prevalence of asthma than other areas, although cough and phlegm are more common. ${ }^{14-16}$ Some of these surveys included tests of skin sensitivity to common inhaled allergens. One study compared children living in urban, industrialised, and rural areas of Italy and found no difference in the prevalence of positive skin tests, although cough and phlegm were more prevalent in the polluted areas. ${ }^{17}$ The authors concluded that air pollution does not increase the prevalence of atopy, although it may enhance the development of symptoms in sensitised subjects. A recent survey found that the prevalence of skin test sensitivity was lower in rural Swedish children than in urban Swedish children, but lower still in urban Polish children exposed to much more sulphur dioxide and smoke pollution than either of the Swedish groups. ${ }^{16}$ The Polish children had more respiratory symptoms than the Swedish children. It is difficult to interpret the findings in terms of the overall effects of pollution, since different pollutants may operate in different ways. A comparison between children in East and West German cities found a higher prevalence of hay fever ${ }^{14}$ and positive skin tests ${ }^{18}$ in Munich than in Leipzig and Halle, where industrial pollution with sulphur dioxide was substantially higher but exposure to vehicle exhaust fumes was lower. Three successive surveys were conducted in Japanese women; an association between chronic wheeze and proximity of residence to a busy road was found in 1979 but not confirmed in 1982 or $1983 .{ }^{19} \mathrm{~A}$ survey in the Scottish Highlands suggested that the prevalence of exercise induced asthma in children is particularly high in Skye, an area with little atmospheric pollution. ${ }^{20}$

Geographical comparisons are potentially liable to the 'ecological fallacy', in that the areas being compared may differ in a number of important respects, and the wrong factor may be singled out as the cause of the variation in prevalence. Experimental studies are required in order to differentiate between the effects of pollutants and other environmental variables.

\section{Evidence from animal experiments}

The inception of allergy can be studied experimentally by means of animal experiments. Studies in several species have shown a potentiation of the allergic response and increased IgE production consequent upon exposure to various pollutants. For example, the IgE antibody responses of mice to intraperitoneal injections of ovalbumin are enhanced by diesel exhaust particulates, both when these are mixed with the injected antigen ${ }^{21}$ and when they are inhaled. ${ }^{22}$ Exposure to sulphur dioxide increases the production of specific antibodies and bronchial responsiveness when guinea pigs inhale ovalbumin. ${ }^{23}$ Exposure to ozone increases the airway responsiveness of dogs to ascaris antigen ${ }^{24}$ and the incidence of positive skin tests in monkeys exposed concurrently to a platinum salt. ${ }^{25}$ The relevance of this work for human disease is not wholly clear, however; the mechanism of allergic response is not necessarily the same in these animals as in man, and the pollutant concentrations have sometimes been much higher than those encountered in ordinary life.

Possible mechanisms

There is a range of possible mechanisms by which air pollution could cause asthma. Exposure of respiratory epithelial cells to ozone or nitrogen dioxide induces the release of inflammatory mediators and proinflammatory cytokines, which may participate in the disease process. ${ }^{26}$ The bronchoconstrictor effect of pollutants seems to be greater in subjects who are atopic or have a history of asthma. ${ }^{27}$ Although this mechanism is more naturally thought of as an aggravation of existing disease, it may be said to cause asthma in so far as it raises the level of symptoms to a point where they attract a diagnosis of asthma.

Then it is possible that air pollutants interact with inhaled allergens, either by modifying the allergens themselves or by facilitating their uptake across the airway epithelium (by increasing epithelial permeability or impairing mucociliary clearance). There is some evidence from laboratory studies of human subjects, ${ }^{26} 28$ human epithelial cells, ${ }^{26}$ and animals ${ }^{29}$ to show that these effects occur.

Finally, there is the possibility that certain pollutants affect the immunological system directly. Some animal experiments have examined the effects of inhaled pollutants on the response to antigens introduced by other routes (for example, by intraperitoneal injection), and have shown a potentiation of IgE production. ${ }^{21}$ If immune mechanisms can be switched on by inhaled substances, then air pollution may truly cause and not merely aggravate asthma.

\section{Conclusions}

Air pollution undoubtedly causes respiratory symptoms both in the short term (after acute episodes) and in the long term (as shown by geographical comparisons). Industrial pollution with sulphur dioxide and smoke does not seem to initiate asthma, although it may increase its severity. Diesel exhaust fumes and ozone may have more profound effects in potentiating the effects of inhaled allergens or in acting on the immunological system. Such effects would fit in with the time trends: the rise in asthma prevalence has coincided with a fall in heavy industrial pollution but an increase in motor vehicle emissions.

Does air pollution cause asthma? Perhaps it does; the case is far from being proved, but the 'newer' pollutants such as ozone, $\mathrm{PM}_{10}$, and diesel emissions are certainly under suspicion.

Centre for Applied Public Health Medicine,

MICHAEL L BURR

Temple of Peace and Health,

Cathays Park,

Cardiff CF1 $3 \mathrm{NW}$

1 Burr ML. Epidemiology of asthma. In: Burr ML, ed. Epidemiology of clinical allergy. Monographs in allergy. Basel: Karger, 1993; 31: 80-102.

2 Andrae $S$, Axelson $O$, Björkstèn B, Fredriksson $M$, Kjellman N-IM. Symptoms of bronchial hyperreactivity and asthma in relation to environmental factors. Arch Dis Child 1988; 63: 473-8.

3 Charpin D, Kleisbauer JP, Fondarai A, et al. Répercussions cliniques et spirométriques d'une exposition chronique aux polluants atmosphériques chez des enfants de la région du bassin de Gardanne. Rev Pneumol Clin 1988; 44: 64-7.

4 A berg N. Asthma and allergic rhinitis in Swedish conscripts. Clin Exp Allergy 1989; 19: 59-63.

5 Laor A, Cohen L, Danon YL. Effects of time, sex, ethnic origin, and area of residence on prevalence of asthma in Israeli adolescents. BMF 1993; 307: 841-4.

6 Thomas E, Fleming DM, Ayres JG. Higher hay fever rates in urban than in rural areas in general practice in the UK, 1981-1990. Thorax 1993; 48: 458.

7 Schmitzberger R, Rhomberg K, Kemmler G. Chronic exposure to ozone and respiratory health of children. Lancet 1992; 339: 881-2.

8 and respiratory health of children. Lancet 1992; 339: 881-2. prevalence of Japanese cedar pollinosis among the residents in a densely prevalence of Japanese cedar pollinosis among

9 Edwards J, Walters S, Griffiths RK. Hospital admissions for asthma in preschool children: relationship to major roads in Birmingham, United

10 Weiland SK, Mundt KA, Rückmann A, Keil U. Self-reported wheezing and allergic rhinitis in children and traffic density on street of residence. Annals of Epidemiology 1994; 4: 243-7.

11 Søyseth V, Kongerud J, Haarr D, Strand O, Bolle R, Boe J. Relation of exposure to airway irritants in infancy to prevalence of bronchial hyperresponsiveness in schoolchildren. Lancet 1995; 345: 217-20. 
12 Dekker C, Dales R, Bartlett S, Brunekreef B, Zwanenburg H. Childhood asthma and the indoor environment. Chest 1991; 100: 922-6.

13 Infante-Rivard C. Childhood asthma and indoor environmental risk factors Am F Epidemiol 1993; 137: 834-44.

14 von Mutius E, Fritzsch C, Weiland SK, Röll G, Magnussen H. Prevalence of asthma and allergic disorders among children in united Germany: a descriptive comparison. BMF 1992; 305: 1395-9.

15 Wjst M, Reitmier P, Dold S, et al. Road traffic and adverse effects on respiratory health in children. $B M F$ 1993; 307: 596-600.

16 Bråbåck L, Breborowicz A, Dreborg S, Knutsson A, Pieklik H, Björkstèn B. Atopic sensitization and respiratory symptoms among Polish and Swedish school children. Clin Exp Allergy 1994; 24: 826-35.

17 Corbo GM, Forastiere $\mathrm{F}$, Dell'Orco $\mathrm{V}$, et al. Effects of environment on atopic status and respiratory disorders in children. $\mathcal{F}$ Allergy Clin Immuno 1993; 92: 616-23.

18 von Mutius E, Martinez FD, Fritzsch C, Nicolai T, Reitmier P, Thiemann H-H. Skin test reactivity and number of siblings. $B M \mathcal{F} 1994$ 308: $692-5$.

19 Nitta H, Sato T, Nakai S, Maeda K, Aoki S, Ono M. Respiratory health associated with exposure to automobile exhaust. I. Results of crosssectional studies in 1979, 1982, and 1983. Arch Environ Health 1993; 48: 53-8.

20 Austin JB, Russell G, Adam MG, Mackintosh D, Kelsey S, Peck DF Prevalence of asthma and wheeze in the Highlands of Scotland. Arch Dis Child 1994; 71: 211-6.
21 Muranaka M, Suzuki S, Koizumi K, et al. Adjuvant activity of dieselexhaust particulates for the production of IgE antibody in mice. $\mathcal{F}$ Allergy Clin Immunol 1986; 77: 616-23.

22 Takafuji S, Suzuki S, Koizumi K, et al. Diesel exhaust particulates inoculated by the intranasal route have an adjuvant activity for IgE production in mice. $\mathcal{f}$ Allergy Clin Immunol 1987; 79: 639-45.

23 Riedel F, Kramer M, Scheibenbogen C, Rieger CH. Effects of $\mathrm{SO}_{2}$ exposure on allergic sensitization in the guinea pig. $\mathcal{f}$ Allergy Clin Immunol 1988; 82: 527-34.

24 Yanai $M$, Ohrui $T$, Aikawa $T$, et al. Ozone increases susceptibility to antigen inhalation in allergic dogs. $\mathcal{f}$ Appl Physiol 1990; 68: 2267-73.

25 Biagini RE, Moorman WJ, Lewis TR, Bernstein IL. Ozone enhancement of platinum asthma in a primate model. Am Rev Respir Dis 1986; 134: platinum

26 Rusznak C, Devalia JL, Davies RJ. The impact of pollution on allergic disease. Allergy 1994; 49: 21-7.

27 Abramson $M$, Voigt T. Ambient air pollution and respiratory disease. Med f Aust 1991; 154: 543-53.

$28 \mathrm{Kehrl} \mathrm{HR,} \mathrm{Vincent} \mathrm{LM,} \mathrm{Kowalsky} \mathrm{RJ,} \mathrm{et} \mathrm{al.} \mathrm{Ozone} \mathrm{exposure} \mathrm{increases} \mathrm{res-}$ piratory epithelial permeability in humans. Am Rev Respir Dis 1987; 135: $1124-8$

29 Matsumura Y. The effects of ozone, nitrogen dioxide and sulfur dioxide on the experimentally induced allergic respiratory disorder in guinea pigs. II. The effects of ozone on the absorption and the retention of antigen in the lung. Am Rev Respir Dis 1970: 102: 438-43.

\section{Guidelines for the administration of blood products}

Earlier this year a document setting out guidelines for the administration of blood products to infants and neonates was published under the authorship of a working party of the British Committee for Standards in Haematology (BCSH) Blood Transfusion Task Force. ${ }^{1}$ These guidelines are the first of their type to be produced in the UK and are to be welcomed. Unfortunately their publication in a specialist transfusion journal has probably meant that they may not have reached a wider paediatric audience.

The authors acknowledge that many accepted practices are not founded wholly on objective investigation. We are uneasy about 'broad agreement' as a basis for firm recommendations. Many would view consensus medicine as a reduction to the lowest common denominator and one which stifles leading edge changes in practice. We believe that a set of guidelines should draw attention to evidence based recommendations but that an important additional role is to highlight uncertainties.

\section{Evidence based recommendations}

In these guidelines some very useful, clear statements are made, with well referenced substantiating evidence. These include widely accepted views such as that walking donor panels are no longer considered appropriate as a source of blood for neonatal transfusions. Others are based on sound evidence but are less widely appreciated, such as that red cell components may safely be used to the end of their full shelf life for small volume neonatal transfusions. ${ }^{2}$ Similarly, the use of satellite packs are an effective means by which to reduce donor exposure in extremely preterm neonates but only if the hospital transfusion laboratory uses them appropriately to the end of their shelf life and ensures the allocation of units to particular infants. ${ }^{3}$ The guidelines set out a clear pretransfusion testing protocol for neonates. This includes an indirect antiglobulin test to exclude atypical antibodies, and emphasises that further screening for red cell antibodies is unnecessary for the first four months after birth. This deserves wide publicity in service laboratories, particularly to those providing on-call services to neonatal units.

\section{Red cell transfusion}

The guidelines also briefly review the indications for red cell transfusions, a contentious area, on which there is an extensive literature. However, no mention is made of the use of erythropoietin, which may change transfusion requirements. ${ }^{4}$ The reader is referred to a recent review of the subject by Luban. ${ }^{5}$ Some uncertainties might have merited more critical discussion. Two prospective studies describe the inability of infants to develop alloantibodies, ${ }^{67}$ and this provides the justification for advising that repeat red cell antibody screening is unnecessary for four months. However, what is the effect of preterm birth on the ability to react to allogeneic red cell antigens? Is the 'first 4 months of age' the same in immunological terms for an infant born at 24 weeks as for one born at 36 weeks? Is there any evidence that birth matures the ability to form red cell alloantibodies and what are the effects of fetal transfusion on the alloimmune process?

\section{Intrauterine transfusion}

It might have been appropriate to have extended the initial brief, to include transfusion of the fetus. In many ways the conceptual division between the fetus and neonate is artificial. Immunological naivety, the ability, or the inability, to react to an alloimmune stimulus, susceptibility to viral infections, and potentially long post-transfusion survival, are shared by both groups of patients. Delayed side effects relating to intrauterine transfusion may be dealt with by neonatal paediatricians and may include suppression of erythropoiesis, transfusion transmitted infection, possible induction of immune tolerance, and transfusion associated graft versus host disease (TA-GVHD).

\section{Graft versus host disease}

The risk of TA-GVHD in fetal and neonatal transfusion practice is small but finite and may be associated with immune naivety and the proportionately large, fresh transfusions containing viable lymphocytes that these tiny patients may receive. There are very few reported cases of neonatal TA-GVHD and this may reflect its rarity, under 